\title{
Approximation of Height of an Individual Using Somatometry of Human Male Skull
}

\author{
Jenash Acharya, ${ }^{1}$ B Suresh Kumar Shetty, ${ }^{2}$ Rijen Shrestha, ${ }^{3}$ Tanuj Kanchan ${ }^{4}$ \\ 'Department of Forensic Medicine, Kathmandu Medical College, Kathmandu, Nepal, ${ }^{2}$ Department of Forensic Medicine \\ and Toxicology, Kasturba Medical College, Mangalore University, Mangalore, India, ${ }^{3}$ Department of Forensic Medicine, \\ Maharajgunj Medical Campus, Institute of Medicine, Kathmandu, Nepal, ${ }^{4}$ Department of Forensic Medicine, All India Institute \\ of Medical Sciences, Jodhpur, India.
}

Introduction: Numerous population specific studies conducted on skeletal remains have aimed to standardize the identification process. Known for ethnic and sexual variations, skull bone can also assist the identification process by estimating stature of the individual. The present study focuses on estimation of stature from skull bone using uni-variate and multi-variate regression models in south Indian population.

Methods: Stature and maximum cranial length, maximum cranial breadth, bi-pterion breadth, parietal cord and upper facial breadth were measured in wet skulls of 113 males, autopsied at Government Hospital of Kudla, Karnataka.

Results: All five measurements showed significant correlation with stature (P value $<0.001)$. MCL showed the highest $(\mathrm{r}=0.77)$ and UFB the lowest $(\mathrm{r}=0.42)$ degree of correlation. Standard error of estimate was lowest for MCL $(4.90 \mathrm{~cm})$ in the derived uni-variate regression models. In the regression model obtained from the multi-variate analysis using all five skull measurements the $\beta$-coefficients were significant $(\mathrm{P}$ value $<0.001)$ and the Standard Error of Estimation of the model was observed to be $4.45 \mathrm{~cm}$. Bland-Altman analysis was conducted to explore the agreement between the actual length and the estimated lengths from the multivariate regression model. The mean of difference was 0.105 with a standard deviation of 4.3 and the upper and lower limits of agreement were 8.5 and -8.3 respectively.

Conclusions: The study concludes that stature can be estimated from skull measurements with reasonable accuracy, observations of multi-variate regression models being more precise than the uni-variate regression models. Data collected from South India was compared with data available for Nepalese population and validates the use of data of Indian population for extrapolation in Nepalese population.

Keywords: identification; linear regression; skull; South India; stature.

\section{INTRODUCTION}

Establishment of the identity of skeletal remains is not only vital for criminal and legal investigations, but also for various social and financial claims. Skeletal remains received from the scene require estimation of
Correspondence: Dr. Rijen Shrestha, Department of Forensic Medicine, Maharaiguni Medical Campus, Institute of Medicine, Kathmandu, Nepal. Email: drrijenshrestha@gmail.com, Phone: +977. 9841135105 
ethnicity, age, sex and stature. Observations are also matched with ante-mortem records provided to aid in identification of remains.

The process of deriving stature from bones started during the days of Rollet and Pearson.1,2 Modern studies have concluded that the results are population specific..$^{3,4}$ Stature estimation studies are far more common for long small bones than for axial skeleton. ${ }^{5-8}$ However skull is commonly encountered due to its resistance to anthropophagic alterations, decomposition and mutilation is the skull bone. ${ }^{9,10}$ While virtual and 3D-imaging techniques have found its way into craniometric analysis; the privilege, especially in cases where mutilated head with soft tissues or better predictors for stature such as long bones are unavailable, these facilities are merely confined to urban centers. ${ }^{11,12}$

South Indian population studies on skull largely focused on age and sex estimation, ${ }^{13,14}$ except for a study by Rao et al. ${ }^{15}$ that used curved measurements of the length of sagittal and coronal sutures among 87 cadavers. Derivation of regression models for estimation of stature from skull bones of denizens in and around Kudla, is therefore required to aid forensic investigators. This study is a pilot study to derive uni-variate and multivariate regression models for stature estimation from different measurements of skull bone for Kudla, South India.

\section{METHODS}

A cross-sectional quantitative study was conducted at Government Hospital Mortuary in Kudla, South India from January to December 2016. The length of the body (stature) and skull measurements were taken during routine autopsy procedure. Ethical Approval was obtained from Government Hospital, Kudla as well as Kasturba Medical College, Mangalore.

All individuals that were autopsied at Government Hospital, Kudla were included in the study

The exclusion criteria for the study included all females, individuals less than 18 years of age or above 60 years of age, individuals with injuries/fracture to the head, individuals with congenital or acquired anomalies altering the shape of the head or stature as well as cases where exact stature could not be established, example - cases of heat stiffening, advanced stage of decomposition, amputation, diseases/deformities etc.

Measurements and techniques: The body was positioned in such a way that back of head, back of both shoulders, buttocks and heels of both the feet lie on the same plane. The stature was taken as the length of the body that was measured using a linear scale calibrated in centimeters. Rigor mortis of all the weight bearing joints was broken before measuring the stature/ length of the body.

During autopsy, the scalp was reflected using coronal incision extending from one mastoid to another and underlying tissues were scraped off for clear field view of the landmarks included in the study. Following skull measurements were taken in the study using spreading calipers calibrated in centimeters:

1. Maximum Cranial Length (MCL): The distance between Glabella and Inion in the mid sagittal plane is measured. Inion is the most prominent part on the external occipital protuberance.

2. Maximum Cranial Breadth (MCB): Maximum width of the skull perpendicular to mid sagittal plane located over parietal eminence on both sides. The points present on both side of the skull that forms termini of the lines of longest cranial breath also known as euryon.

3. Upper Facial Breath (UFB): The distance between two points on the fronto-malar suture

4. Parietal Cord (PC): The distance between a point in Skull in the mid sagittal plane where coronal and sagittal suture intersect (Bregma) and a point where lambloid and sagittal suture (Lambda).

5. Bi-Pterion distance (BPB): Pterion is the junction of greater wing of sphenoid, squamous, temporal, frontal and parietal bones.

The data was analyzed using SPSS (Statistical Program for Social Sciences) version 17.0 to establish correlation between the skull measurements and length of the body. Uni-variate and multi-variate regression models were derived for estimation of stature based on regression analysis. The level of significance was set at $P$ value $<0.05$.

\section{RESULTS}

The study was conducted on 113 male individuals autopsied at Government Hospital Mortuary, Kudla. The mean stature of the sample population was found to be $164.47 \pm 7.63$, ranging between $143 \mathrm{~cm}$ and $184 \mathrm{~cm}$ (Table 1). All measurements were found to be significantly correlated to the length of the body. MCL showed the highest $(r=0.770)$ and UFB the lowest $(r=0.415)$ correlation (Table 2$)$.

Uni-variate regression models for skull measurements were derived and all skull measurements showed significant correlation with stature $(P$-value $<0.001)$. 
The standard error of estimate (SEE) was the lowest for uni-variate regression model using $\mathrm{MCL}(4.90 \mathrm{~cm})$ indicating a greater reliability in estimating stature using this measurement compared to the others (Table 3).

Multi-variate regression model using all five cranial measurements was derived and all variables were observed to be statistically significant $(P$ value $<0.001)$ with SEE of $4.45 \mathrm{~cm}$ (Table 4).

\begin{tabular}{|c|c|c|c|c|}
\hline Variable & Minimum & Maximum & Mean & SD \\
\hline $\begin{array}{l}\text { Length (in } \\
\mathrm{cm} \text { ) }\end{array}$ & 143.0 & 184.0 & 164.47 & 7.63 \\
\hline $\begin{array}{l}\text { MCL (in } \\
\mathrm{cm} \text { ) }\end{array}$ & 14.5 & 17.0 & 15.924 & 0.83 \\
\hline $\begin{array}{l}\text { MCB (in } \\
\mathrm{cm})\end{array}$ & 9.5 & 14.0 & 11.27 & 0.83 \\
\hline $\begin{array}{l}\text { UFB (in } \\
\mathrm{cm} \text { ) }\end{array}$ & 9.0 & 13.0 & 10.93 & 0.66 \\
\hline $\begin{array}{l}\mathrm{PC} \text { (in } \\
\mathrm{cm} \text { ) }\end{array}$ & 9.0 & 12.0 & 10.83 & 0.67 \\
\hline $\begin{array}{l}\text { BPB (in } \\
\mathrm{cm} \text { ) }\end{array}$ & 9.0 & 13.0 & 11.062 & 0.71 \\
\hline
\end{tabular}

MCL - Maximum Cranial Length; MCB - Maximum Cranial Breadth; UFB - Upper Facial Breadth; PC - Parietal Chord; BPB - Bi-pterion Breadth; SD - Standard Deviation

\begin{tabular}{|lll|}
\hline \multicolumn{3}{|l|}{$\begin{array}{l}\text { Table 2. Correlation between length and various } \\
\text { skull measurements }(\mathbf{n}=113) .\end{array}$} \\
\hline Variable & $\begin{array}{l}\text { Pearson's correlation } \\
\text { coefficient }(\mathbf{r})\end{array}$ & P value \\
MCL & 0.770 & $<0.001$ \\
MCB & 0.515 & $<0.001$ \\
UFB & 0.420 & $<0.001$ \\
PC & 0.415 & $<0.001$ \\
BPB & 0.542 & $<0.001$ \\
\hline
\end{tabular}

MCL - Maximum Cranial Length; MCB - Maximum Cranial Breadth; UFB - Upper Facial Breadth; PC - Parietal Chord;

BPB - Bi-pterion Breadth

\begin{tabular}{|c|c|c|c|c|}
\hline \multicolumn{5}{|c|}{$\begin{array}{l}\text { Table } 3 \text {. Uni-variate linear regression models for } \\
\text { estimation of stature from skull measurements. }\end{array}$} \\
\hline Variable & $\begin{array}{l}\text { Regression } \\
\text { equation }\end{array}$ & $\mathbf{R}^{2}$ & $\begin{array}{l}\text { SEE } \\
(\mathrm{cm})\end{array}$ & $P$ value \\
\hline MCL & $\begin{array}{l}11.375 \times \mathrm{MCL}- \\
16.658\end{array}$ & 0.592 & 4.90 & $<0.001$ \\
\hline MCB & $\begin{array}{l}4.742 \times \mathrm{MCB}+ \\
111.031\end{array}$ & 0.265 & 6.57 & $<0.001$ \\
\hline
\end{tabular}

\begin{tabular}{|lllll} 
UFB & $\begin{array}{l}4.846 \times \mathrm{UFB}+ \\
111.462\end{array}$ & 0.177 & 6.96 & $<0.001$ \\
& $\begin{array}{l}11.926 \times \mathrm{PC}+ \\
\text { PC }\end{array}$ & 0.172 & 6.98 & $<0.001$ \\
BPB & $\begin{array}{l}110.746 \\
100.362\end{array}$ & 0.294 & 6.44 & $<0.001$ \\
\hline
\end{tabular}

MCL - Maximum Cranial Length; MCB - Maximum Cranial Breadth; UFB - Upper Facial Breadth; PC - Parietal Chord;

BPB - Bi-pterion Breadth; SEE - Standard Error of Estimate

Table 4. Multi-variate linear regression model for estimation of stature from skull measurements.

\begin{tabular}{|llll|}
\hline $\begin{array}{l}\text { Regression model using all } \\
\text { five skull measurements }\end{array}$ & $\mathbf{R}^{2}$ & $\begin{array}{l}\text { SEE } \\
(\mathbf{c m})\end{array}$ & P value \\
$0.409 \times \mathrm{UFB}+1.498 \times \mathrm{BPB}+$ & & & \\
$\begin{array}{l}1.073 \times \mathrm{MCB}+1.511 \times \mathrm{PC}+ \\
9.056 \times \mathrm{MCL}-29.375\end{array}$ & 0.675 & 4.45 & $<0.001$ \\
\hline
\end{tabular}

MCL - Maximum Cranial Length; MCB - Maximum Cranial Breadth; UFB - Upper Facial Breadth; PC - Parietal Chord;

\section{BPB - Bi-pterion Breadth; SEE - Standard Error of Estimate}

Bland-Altman analysis was conducted to explore the agreement between the actual length and the estimated lengths from the multivariate regression model (Figure. 1). The mean of difference was 0.105 with a standard deviation of 4.3 and the upper and lower limits of agreement were 8.5 and -8.3 respectively.

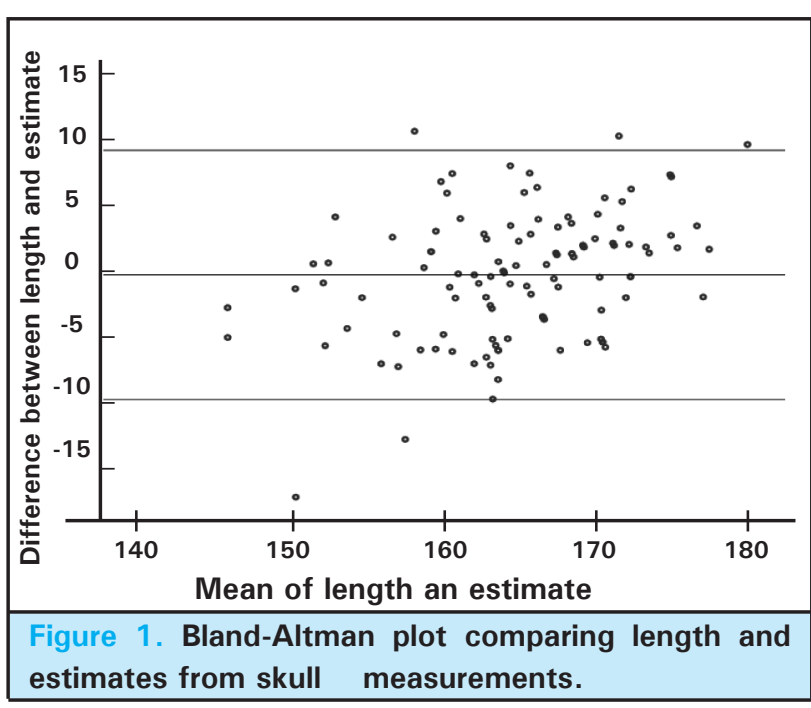

Barring a few outliers, the majority of points in the Bland-Altman plot lay within the limits of agreement.

\section{DISCUSSION}

The onus and challenges on shoulders of forensic experts to identify an individual who at times are 
brought to them as "unidentified individuals" can get complicated if the deceased is in mutilated or skeletonised form. It is neither a rare incident where investigating officers approach with a single bone nor is their expectation from forensic experts to provide them with utmost information regarding the victim from the same. Regression models for estimation of stature have always helped investigators to come up with an estimated range of stature applicable to specific population groups, and skull bone is rare but equally encountered bone.

Itrona et al. concluded in their study that the best correlation of stature was found with maximum cranial length (anterior-posterior diameter) and maximum cranial breadth (lateral diameter) of a skull. ${ }^{16}$ Chiba and Terazawa in their study observed correlation coefficient for maximum cranial length of male subjects to be 0.39. The S.E of regression equation of male subjects in the study was $6.96 \mathrm{~cm}$ which reduced to $6.80 \mathrm{~cm}$ if subjects more than 70 years of age were excluded from the study. ${ }^{17}$ In the present study, all subjects were below 60 years of age; and the Pearson's coefficient was found to have stronger strength $(r=0.77)$ between maximum cranial length and stature as well. The regression models using all five variables in our study showed analogous standard error of estimate $(4.45 \mathrm{~cm})$ with study conducted by Ryan and Bidmos, ${ }^{18}$ where standard error of uni-variate regression for maximum cranial length was found to be lowest $(4.895 \mathrm{~cm})$ whereas basi-bregmatic height in males presented with best correlation coefficient $(0.49-0.54)$ in multi-variate analysis.

Krishan conducted a study among different population group taking 5 linear dimensions of skulls of North Indian males where he observed SEE ranging between 4.136 and $5.820 \mathrm{~cm} .{ }^{19}$ Kishan and Kumar observed a SEE of 4.41 to $7.21 \mathrm{~cm}$ in a study where they measured 16 cephalo-facial dimensions of 252 endogamous group adolescent from North India. ${ }^{20}$ They concluded that cephalic measurements showed better correlation with stature when compared to facial measurements, which was similar to our observations where upper facial breath showed a relatively weaker correlation with stature.

Pelin et al, in a study conducted among Turkish individuals however reported very low correlation coefficients of cephalo-facial dimensions with stature which ranged between 0.012 and 0.229 and stated that stature estimation from cephalo-facial dimensions does not bear much of scientific and mathematical consistence to be used for forensic practice. ${ }^{21}$ In the present study, while maximum cranial length provided high degree of correlation with stature, lower correlations were observed for the parietal chord and upper facial breadth.

Results found in study conducted by Sahni et al however, had lesser SEE (3.56-3.70 cm) where only facial measurements were taken from a population of Northwest India that correlated well with stature. ${ }^{22}$

Shrestha et al, in a similar study to ours had included 2 facial and 3 cranial measurements from 200 autopsied bodies to derived uni-variate and multi-variate regression models for estimating stature in Nepalese population, where SEE was found to be least for Maximum cranial length and showed better correlation with stature in both males and females. ${ }^{23}$ Our observations are thus, similar to the observations made in Nepalese population.

The limitations of our study includes the fact that the study was conducted in one center in Kudla and may not be representative of the entire population. The authors recommend that a study with larger sample size be conducted at multiple centers to increase reliability of the data. The authors also recommend conducting research to study correlation in females.

\section{CONCLUSIONS}

Maximum cranial length was found to have strongest correlation with stature. The results obtained are consistent with other studies carried out throughout the world. Degrees of correlation were found to be population specific, attributable to geographical, nutritional or genetic variation.

The study concludes that stature can be estimated from skull measurements with reasonable accuracy, with multi-variate regression models being more precise than the uni-variate.

While the need for population specific regression models should be emphasized, our study shows that it is possible to extrapolate data for use in similar populations. This should however, be used with caution to ensure accuracy and scientific standards.

\section{Conflict of Interest: None.}




\section{REFERENCES}

1. Rollet E. De la mensuration des os longs des membres dans ses rapports avec l'anthropologie, la clinique et la medecine judiciaire. [dissertation] Lyon, France: Hospitaux de Lyon, 1888. [in French]

2. Pearson K. Mathematical Contributions to the Theory of Evolution. V. On the Reconstruction of the Stature of Prehistoric Races. Philosophical Transactions of the Royal Society A: Mathematical, Physical and Engineering Sciences. 1899;192(0):169-244. [Full Text | DOI]

3. İşcan MY, Steyn M. The human skeleton in forensic medicine.3rd ed. Springfield, Illinois, U.S.A.: Charles C Thomas Publisher Ltd; 2013. [Full Text]

4. Krishan K, Kanchan T. Stature and Build. In: Siegel JA and Saukko P (eds): Encyclopedia of Forensic Sciences. Waltham: Academic Press, Elsevier, 2013;1:49-53 [Full Text]

5. Kanchan T, Kumar G, Menezes R. Index and ring finger ratio-A new sex determinant in south Indian population. Forensic Sci Int. 2008 Oct 25;181(1-3):53.e1-53.e4. [PubMed | DOI ]

6. Ozaslan A, Koç S, Özaslan İ, et al. Estimation of Stature from Upper Extremity. Mil Med. 2006 Apr;171(4):288-291. [PubMed | Full Text | DOI]

7. Torimitsu S, Makino Y, Saitoh H, et al. Stature estimation in Japanese cadavers using the sacral and coccygeal length measured with multidetector computed tomography. Leg Med. (Tokyo) 2014 Jan;16(1):14-19. [PubMed | DOI]

8. Hasegawa, K. Uenishi, T. Fukunaga, et al. Stature estimation formulae from radiographically determined limb bone length in a modern Japanese population, Leg Med. (Tokyo) 2009 Nov;11:260-266. [PubMed | DOI]

9. O'Connor WG. Briefly unidentified: a study of peculiar source of identification. J Forensic Sci. 1999 Jul;44:713-5. [PubMed]

10. Puschel K, Koops E. Dismemberment and mutilation (2). Arch Kriminol. 1987 Sep-Oct;180(3-4):88-100. [PubMed]

11. Giurazza F, Del Vescovo R, Schena E, et al. Determination of stature from skeletal and skull measurements by CT scan evaluation. Forensic Sci Int. 2012 Oct 10;222(1-3):398.e1-398. e9. [PubMed | DOI]
12. Torimitsu S, Makino $\mathrm{Y}$, Saitoh $\mathrm{H}$, et al. Stature estimation from skull measurements using multidetector computed tomographic images: A Japanese forensic sample. Leg Med (Tokyo). 2016 Jan;18:75-80. [PubMed | DOI]

13. Raghavendra Babu Y, Kanchan T, Attiku Y, et al. Sex estimation from foramen magnum dimensions in an Indian population. J Forensic Leg Med. 2012 Apr;19(3):162-167. [PubMed | DOI]

14. Kanchan T, Gupta A, Krishan K. Estimation of sex from mastoid triangle - A craniometric analysis. J Forensic Leg Med. 2013 Oct;20(7):855-860. [PubMed | DOI]

15. Jagadish Rao P, Sowmya J, Yoganarasimha $\mathrm{K}$, et al. Estimation of stature from cranial sutures in a South Indian male population. Int J Legal Med. 2009 May;123(3):271-276. [PubMed | DOI]

16. F. Introna Jr., G. Di Vella, S. Petrachi. Determination of height in life using multiple regression of skull parameters, Boll Soc Ital Biol Sper. 1993 Mar;69:153-160. [PubMed]

17. Chiba M, Terazawa K. Estimation of stature from somatometry of skull. Forensic Sci Int. 1998 Nov;97(2-3):87-92. [PubMed | DOI]

18. Ryan, M.A. Bidmos. Skeletal height reconstruction from measurements of the skull in indigenous South Africans, Forensic Sci Int. 2007 Mar 22;167:16-21. [PubMed | DOI]

19. Krishan K. Estimation of stature from cephalo-facial anthropometry in north Indian population. Forensic Sci Int. 2008 Oct 25;181(1-3):52.e1-52.e6. [PubMed | DOI]

20. Krishan K, Kumar R. Determination of stature from cephalo-facial dimensions in a North Indian population. Leg Med (Tokyo). 2007 May;9(3):128-133. [PubMed | DOI]

21. Pelin C, Zağyapan R, Yazıcı C, et al. Body Height Estimation from Head and Face Dimensions: A Different Method. J Forensic Sci. 2010 Sep;55(5):1326-1330. [PubMed | DOI]

22. Sahni D, Jit I, Neelam, et al. Time of closure of cranial sutures in northwest Indian adults. Forensic Sci Int. 2005 Mar 10;148(2-3):199-205. [PubMed | DOI]

23. Shrestha $\mathrm{R}$, Shrestha $\mathrm{P}$, Wasti $\mathrm{H}$, et al. Craniometric analysis for estimation of stature in Nepalese population- A study on an autopsy sample. Forensic Sci Int. 2015 Mar;248:187.e1-187. e6. [PubMed | DOI] 